\title{
Total Dairy, Cheese and Milk Intake and Arterial Stiffness: A Systematic Review and Meta-analysis of Cross-Sectional Studies
}

\author{
Ana Diez-Fernández ${ }^{1,2}$ (), Celia Álvarez-Bueno ${ }^{1,2, *}$, Vicente Martínez-Vizcaíno ${ }^{1,3}$, \\ Mercedes Sotos-Prieto ${ }^{4,5,6}{ }^{D}$, José I Recio-Rodríguez ${ }^{7,8} \mathbb{D}^{\mathbb{D}}$ and Iván Cavero-Redondo ${ }^{1,2}$ \\ 1 Centro de Estudios Socio-Sanitarios, Universidad de Castilla-La Mancha, 16071 Cuenca, Spain; \\ ana.diez@uclm.es (A.D.-F.); Vicente.martinez@uclm.es (V.M.-V.); Ivan.Cavero@uclm.es (I.C.-R.) \\ 2 Facultad de Enfermería, Universidad de Castilla-La Mancha, 16071 Cuenca, Spain \\ 3 Facultad de Ciencias de la Salud, Universidad Autónoma de Chile, 1670 Talca, Chile \\ 4 Department of Environmental Health, Harvard TH Chan School of Public health, Harvard Medical School, \\ Boston, MA 02115, USA; sotospri@ohio.edu \\ 5 Department of Food Sciences and Nutrition, School of Applied Health Sciences and Wellness, \\ Ohio University, Athens, $\mathrm{OH} 45701$, USA \\ 6 Diabetes Institute, Ohio University, Athens, OH 45701, USA \\ 7 Institute of Biomedical Research of Salamanca (IBSAL), Primary Health Care Research Unit, \\ La Alamedilla Health Center, Health Service of Castilla y León (SACYL), Primary Care Prevention and \\ Health Promotion Research Network (REDIAPP), 37007 Salamanca, Spain; donrecio@gmail.com \\ 8 Departamento Enfermería y Fisioterapia, Universidad de Salamanca, 37007 Salamanca, Spain \\ * Correspondence: Celia.alvarezbueno@uclm.es; Tel.: +34-969-179-100 (ext. 4659)
}

Received: 27 January 2019; Accepted: 23 March 2019; Published: 29 March 2019

\begin{abstract}
The aim of this review was to determine the relationship between dairy product consumption and arterial stiffness, measured by pulse wave velocity (PWV). We systematically searched the Medline, Embase and Web of Science databases until 30 January 2019 for cross-sectional data from studies addressing the association between dairy product consumption and PWV. This study was registered with PROSPERO (CRD42018110528). Both the inverse-variance fixed effects method and the DerSimonian and Laird method were used to compute pooled estimates of effect size (ES) and the respective 95\% confidence intervals (CIs). Seven studies were included in the meta-analysis, with a total of 16,443 patients. Total dairy product $(\mathrm{ES}=-0.03 ; 95 \% \mathrm{CI}[-0.04$, $-0.01]$ ) and cheese (ES $=-0.04 ; 95 \% \mathrm{CI}[-0.07,-0.01])$ consumption were weak, but significantly associated with lower PWV levels. Conversely, milk intake showed no significant association with PWV (ES $=0.02 ; 95 \%$ CI $[-0.01,0.05])$. Heterogeneity in the ES was not important for the three groups of dairy products assessed. This systematic review and meta-analysis of seven studies found no detrimental effects of dairy product consumption on arterial stiffness measured by PWV. Due to the scarcity of studies, further investigations are warranted to clarify the role of dairy products on arterial stiffness.
\end{abstract}

Keywords: arterial stiffness; pulse wave velocity; dairy product; milk; meta-analysis; systematic review

\section{Introduction}

Cardiovascular disease (CVD) represents the main cause of mortality worldwide [1]. Certain behaviors, such as an unhealthy diet and physical inactivity, have increased in parallel with the prevalence of CVD risk factors, including obesity, hypertension and diabetes. Increasingly, evidence from longitudinal studies consistently supports a negative association between dairy product intake 
and the risk of CVD, which is in accordance with observational studies that report a negative association between milk intake and obesity [2], diabetes [3] and hypertension [4]. Moreover, a recent meta-analysis of prospective studies have also shown a null or weak inverse effect of dairy products on CVD [5].

Similarly, recent studies have reported that dairy product intake is associated with other CVD risk indicators, such as arterial stiffness [6]. A characteristic of the aging process is the stiffening of large arteries, which may promote the progression of some chronic diseases, particularly hypertension. Conversely, certain behaviors, such as smoking, a sedentary lifestyle or unhealthy diet, and certain cardiometabolic diseases, such as obesity and type 2 diabetes mellitus, are consistently correlated with the progression of arterial stiffness [7-9].

Dairy products include milk, cream, butter, cheese, yogurt, frozen desserts and whey, among others. They contain several micro- and macronutrients, including saturated fatty acids (SFAs). Indeed, the SFA content is the main reason why dairy product intake has received an unfavorable reputation in recent years [10]. The literature examining the relationship between dairy product intake and arterial stiffness is scarce and findings are inconsistent, although recent results from the Prospective Urban Rural Epidemiology (PURE) multinational cohort study suggest that dairy consumption might be associated with a lower risk of mortality and major cardiovascular disease events [11]. Moreover, recent meta-synthesis studies have addressed the relationship between milk and dairy consumption and CVD [12], diabetes [13] and all-cause mortality [14].

Increased aortic pulse wave velocity (PWV), the most valid and reliable measure of arterial stiffness, has been associated with a higher risk of cardiovascular events and all-cause mortality. A systematic review and meta-analysis [6] reported that the prediction ability of arterial stiffness is higher in subjects at increased risk of cardiovascular disease, estimating a $14 \%$ increase in total cardiovascular risk with every $1 \mathrm{~m} / \mathrm{s}$ increase in PWV. Among the indexes proposed to estimate PWV, carotid-femoral pulse wave velocity (cfPWV) is accepted as the gold standard noninvasive method [15].

This systematic review and meta-analysis aimed to synthesize the evidence of the relationship between the consumption of dairy products and arterial stiffness (measured by PWV).

\section{Materials and Methods}

This systematic review and meta-analysis is reported according to the Preferred Reporting Items for Systematic Reviews and Meta-analyses (PRISMA) guidelines [16] (Figure 1), and follows the recommendations of the Cochrane Collaboration Handbook [17]. The study was also registered through the International Prospective Register of Systematic Reviews (registration number: CRD42018110528).

\subsection{Data Sources and Searches}

We systematically searched MEDLINE (via PubMed), EMBASE and Web of Science databases from their inception until 30 January 2019. The search strategy included, combined with Boolean operators, the following terms: milk, dairy, dairy product, dairy product consumption, dairy product intake, dairy intake, pulse wave velocity, arterial stiffness, PWV, arterial aging, aortic stiffness (Table 1). The literature search was complemented by reviewing the reference lists of articles considered eligible for the systematic review. Authors were contacted to obtain missing information when necessary. 


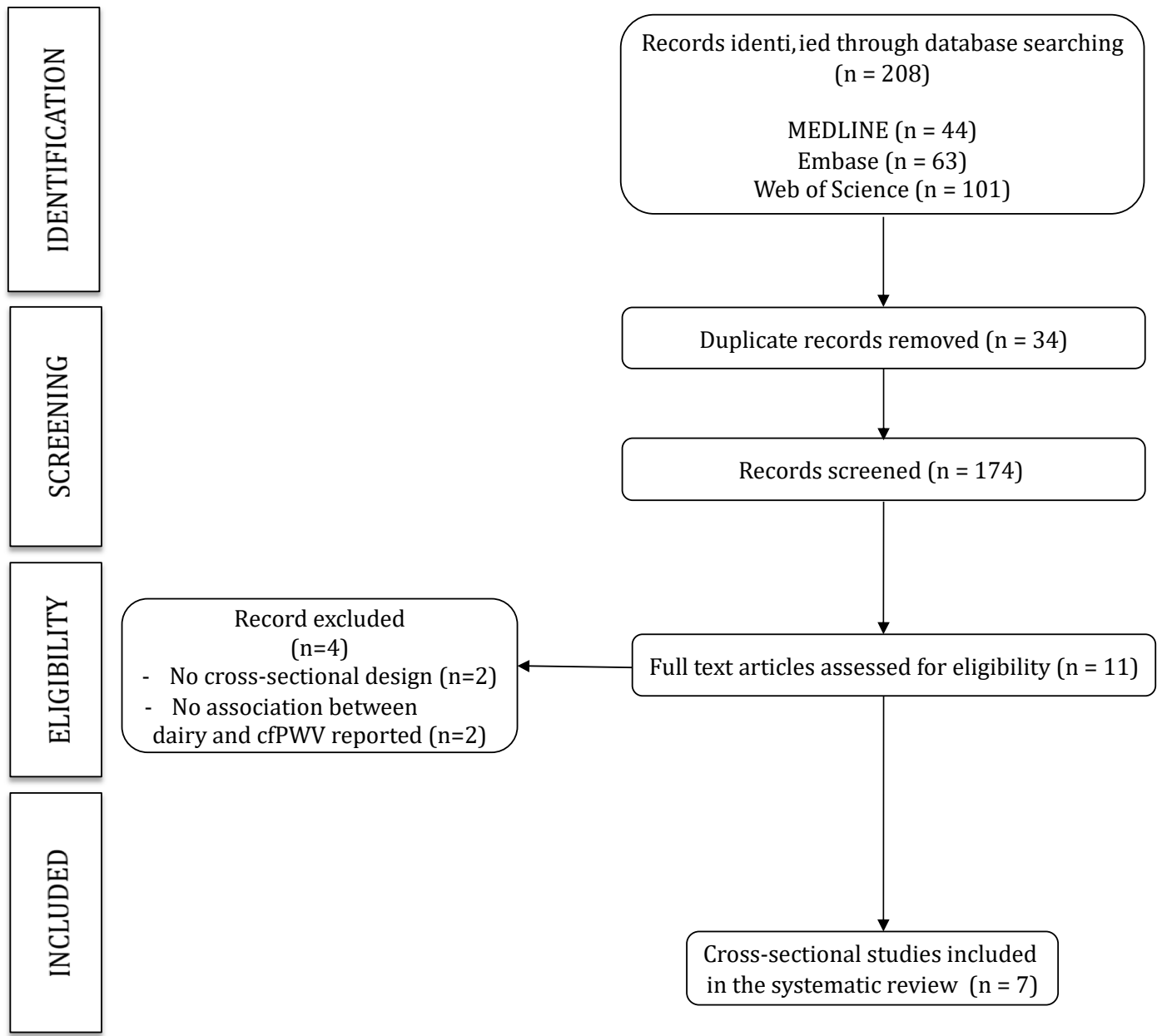

Figure 1. Literature search PRISMA (Preferred Reporting Items for Systematic Reviews and Meta-analyses) consort diagram.

Table 1. Search strategy for Medline.

\begin{tabular}{cc}
\hline Dairy Related Terms & Arterial Stiffness Related Terms \\
\hline "milk" & "pulse wave velocity" \\
OR & OR \\
"dairy" & "arterial stiffness" \\
OR & OR \\
"dairy product" & "PWV" \\
OR & OR \\
"dairy product consumption" & AND \\
OR & "arterial aging" \\
"dairy product intake" & OR \\
OR & "aortic stiffness" \\
"dairy intake" & \\
\hline
\end{tabular}

\subsection{Study Selection}

The criteria for including studies were as follows: (i) individuals from population-based samples; (ii) study design including cross-sectional studies or baseline measurements of cohort studies and RCTs; (iii) exposure to dairy products consumption, milk, cheese, yogurt, butter or other type of dairy product; and (iv) arterial stiffness as the outcome, measured using PWV. The criteria for excluding studies were as follows: (i) reports not written in English or Spanish; and (ii) non-eligible publication types, such as review articles, editorials, comments, guidelines or case-reports. 
The literature search was independently conducted by two reviewers (AD-F and IC-R), and disagreements were resolved by consensus or by consultation with a third researcher (CA-B).

\subsection{Data Extraction and Quality Assessment}

The following data were extracted from the original reports: (1) first author and year of publication; (2) country where data for the study were collected; (3) sample characteristics (type of design, sample size, average age and distribution, average systolic blood pressure (SBP), average diastolic blood pressure (DBP) and average body mass index (BMI)); (4) type of record and quantity of dairy products consumed; and (5) PWV mean value, measurement site and device used.

The Quality Assessment Tool for Observational Cohort and Cross-sectional Studies published by the National Heart, Lung and Blood Institute was used to evaluate the risk of bias of cohort and cross-sectional studies [18]. The methodological criteria included: research question, population definition, participation rate, recruitment, sample size, analysis, timeframe, exposure levels, measures and assessment, outcome measures and blinding, loss to follow-up, and confounding variables. Each study was rated as either good (i.e., most criteria met with a low risk of bias), fair (i.e., some criteria met with a moderate risk of bias), or poor (i.e., few criteria met and with a high risk of bias). Rating of studies was independently performed by two reviewers (AD-F and IC-R), and inconsistencies were resolved by consensus or by consulting a third researcher (CA-B).

\subsection{Statistical Analysis}

Both the inverse-variance fixed effects method [19] and the DerSimonian and Laird method were used to compute pooled estimates of effect size (ES) and the respective $95 \%$ confidence intervals (CI). When studies presented this association by regression models or mean value trends by group, the ES [20] was calculated. Values of ES of around 0.2 were considered a weak effect, values around 0.5 indicated a moderate effect, values around 0.8 represented a strong effect, and values larger than 1.0 were considered a very strong effect. Considering the differing composition of dairy products, the meta-analysis considered the type of dairy products, the pooled estimates by the type of dairy products were calculated only when there was three or more studies (total, milk and cheese); thus, other type of dairy products, such as cream, butter, yogurt, frozen desserts or whey were not individually analyzed. The heterogeneity of results across studies was assessed using the I2 statistic. I2 values were considered as: 0-40\%, might not be important; 30-60\%, may represent moderate heterogeneity; $50-90 \%$, substantial heterogeneity; or $75-100 \%$, considerable heterogeneity. The corresponding $\mathrm{p}$-values were also taken into account [17].

Sensitivity analyses (systematic re-analysis while removing studies one at a time) were conducted to assess the robustness of the summary estimates and to provide insight as to whether any particular study accounted for a large proportion of heterogeneity amongst the pooled ES.

Random-effects meta-regression analyses were performed to determine whether age, BMI, SBP, DBP or pulse pressure (PP) were significant moderators for the relationship between dairy products and PWV.

Publication bias was assessed by the Harbord modified test [21], and was considered statistically significant at a $p$-value of $<0.10$. Statistical analyses were performed using Stata/SE software version 14 (College Station, TX, USA).

\section{Results}

\subsection{Systematic Review}

The PRISMA flow diagram is presented in Figure 1. From the 208 full-text articles identified, only seven studies met the inclusion criteria and were included in the systematic review. These studies were published between 2012 and 2018, included sample sizes ranging from 22 to 12,892 participants, and data was collected from samples from Europe, North and South America and Oceania. A total 
of 16,427 patients met the inclusion criteria and were included in the analysis. Six studies included an adult population (mean age ranged from $26.3 \pm 4.2$ to $63.8 \pm 12.4$ years) [22-27], and one study included children and adolescent patients (13.2 \pm 0.7 years) [28]. All studies determined arterial stiffness through the carotid-femoral PWV, with six studies using the SphygmoCor system (AtCor Medical Pty Ltd., West Ryde, Australia) while the other one used the Complior automatic device (Artech Medical, France) [24]. Dairy product consumption was estimated with different questionnaires that recorded the frequency and type of dairy product consumed (Table 2).

Of the studies reviewed, five focused on overweight participants $[23-25,27,28]$ while the remaining two studies included obese samples [22,26]. Furthermore, five studies focused on subjects with elevated blood pressure (BP), one study focused on subjects with normal BP, and the other study focused on subjects with stage 1 hypertension [25] (Table 2).

Six studies analyzed the consumption of total dairy products [22-27] and one only included milk intake [28]. Milk and cheese could be analyzed separately since four [24-26,28] and three studies [24-26], respectively, included the information. Butter and yogurt could not be analyzed due to the lack of results in the studies (only one study included butter [24] and two included yogurt [24,26]).

Four studies showed negative associations between total dairy products and PWV [22-24,26] while two found a positive association [25,27]. Regarding milk intake, two studies found a negative association with PWV [26,28] and the other two describe a positive association $[24,25]$. Finally, cheese consumption was negatively associated with PWV in all included studies [24-26]. It is remarkable that all associations between total dairy products, milk and cheese with PWV were discrete.

Each study used a different questionnaire to assess participant's dietary records. Among their similarities, three of them presented their results across categories of frequency of consumption of dairy products [23-25]. Two studies collected the data through electronic versions of the questionnaires [22,26], three collected the data at the moment of the interview [24,25,27], one required participants to fulfil a booklet every day for four days [28] and other was completed within 2 weeks of the laboratory visit by the participants [23].

Age was included as a covariate in all studies, and most of them also included as covariates anthropometric (BMI or waist circumference) [22-24,26,28], biochemical (high-density lipoprotein (HDL) and/or low-density lipoprotein (LDL) cholesterol, triglycerides (TG)) $[23,24,27,28]$, the use of antihypertensive medication [23-27] and some blood pressure-related variables such as mean arterial pressure (MAP) or SBP (Table 2). 
Table 2. Characteristics of the studies included.

\begin{tabular}{|c|c|c|c|c|c|c|c|c|c|c|}
\hline Study & $\begin{array}{l}\text { Country/Type } \\
\text { of Design }\end{array}$ & $\begin{array}{l}\text { n/Mean Age } \\
\text { (Years) }\end{array}$ & $\begin{array}{c}\text { Mean BMI } \\
\left(\mathrm{kg} / \mathrm{m}^{2}\right)\end{array}$ & $\underset{(\mathrm{mmHg})}{\text { Mean SBP/DBP }}$ & $\begin{array}{c}\text { Mean PWV } \\
(\mathrm{m} / \mathrm{sec})\end{array}$ & Dietary Record & $\begin{array}{l}\text { Type of Dairy } \\
\text { Product }\end{array}$ & $\begin{array}{l}\text { Mean Dairy } \\
\text { Products } \\
\text { Consumption }\end{array}$ & Main Results & Covariables \\
\hline $\begin{array}{c}\text { Arnberg Ket al, } \\
2012[28]\end{array}$ & $\begin{array}{c}\text { Denmark/ } \\
\text { Cross-sectional }\end{array}$ & $193 / 13.2 \pm 0.7$ & $25.2 \pm 2.3$ & $111 \pm 7 / 65.3 \pm 6.3$ & $4.81 \pm 0.71$ & $\begin{array}{l}\text { Precoded food } \\
\text { record of } 4 \text { days [29] }\end{array}$ & Milk & $224 \mathrm{~g} / \mathrm{d}$ & $\begin{array}{l}\text { Negative association } \\
\text { between milk intake } \\
\text { and PWV. }\end{array}$ & $\begin{array}{l}\text { Age, gender, MAP, Tanner } \\
\text { stage, heart rate, HOMA, } \\
\text { serum TG, serum HDL } \\
\text { cholesterol and BMI. }\end{array}$ \\
\hline $\begin{array}{l}\text { Campbell M et } \\
\mathrm{al}, 2018[22]\end{array}$ & $\begin{array}{l}\text { USA/ } \\
\text { Cross-sectional }\end{array}$ & $22 / 26.3 \pm 4.2$ & $33.2 \pm 3.5$ & $124.3 \pm 8.5 / 79.5 \pm 7.6$ & $6.34 \pm 0.88$ & $\begin{array}{l}\text { DHQ-II of one } \\
\text { month [30] }\end{array}$ & Dairy products & $194.25 \mathrm{~g} / \mathrm{d}$ & $\begin{array}{l}\text { Negative correlation } \\
\text { between dairy products } \\
\text { and PWV. }\end{array}$ & $\begin{array}{l}\text { Age, BMI, MAP, SBP, PP and } \\
\text { waist circumference. }\end{array}$ \\
\hline $\begin{array}{l}\text { Crichton G et al, } \\
2012[23]\end{array}$ & $\begin{array}{c}\text { USA/ } \\
\text { Cross-sectional }\end{array}$ & $587 / 63.8 \pm 12.4$ & $29.5 \pm 6.4$ & $128.9 \pm 19.6 / 77 \pm 9.3$ & $10.25 \pm 2.8$ & $\begin{array}{l}\text { Nutrition and } \\
\text { Health } \\
\text { questionnaire [31] }\end{array}$ & $\begin{array}{l}\text { Milk and dairy } \\
\text { product }\end{array}$ & NA & $\begin{array}{l}\text { According to categories } \\
\text { of dairy products } \\
\text { frequency consumption, } \\
\text { higher intake of dairy } \\
\text { food was related with } \\
\text { lower PWV, PP, and } \\
\text { SBP values. }\end{array}$ & $\begin{array}{l}\text { Age, education, sex, race, } \\
\text { weight, heart rate, } \\
\text { antihypertensive drug } \\
\text { treatment, MAP, waist } \\
\text { circumference, total cholesterol, } \\
\text { HDL and LDL cholesterol, } \\
\text { Center for Epidemiologic } \\
\text { Studies Depression Scale raw } \\
\text { score + grains per day, } \\
\text { vegetables per day, sweets per } \\
\text { day, protein per day, and total } \\
\text { food servings per day. }\end{array}$ \\
\hline $\begin{array}{l}\text { Gomes Ribeiro } \\
\text { A et al, 2018 [24] }\end{array}$ & $\begin{array}{c}\text { Brazil/ } \\
\text { Cross-sectional }\end{array}$ & $12892 / 51.6 \pm 8.9$ & $26.8 \pm 4.6$ & $\begin{array}{l}121.1 \pm 17.1 / \\
76.3 \pm 10.7\end{array}$ & $9.31 \pm 1.81$ & $\begin{array}{l}\text { Semi-quantitative } \\
\text { FFQ [32] }\end{array}$ & $\begin{array}{l}\text { Milk, cheese, } \\
\text { yogurt, butter }\end{array}$ & $316.60 \mathrm{~g} / \mathrm{d}$ & $\begin{array}{l}\text { Inverse association } \\
\text { between the intake of } \\
\text { dairy products with } \\
\text { SBP, PP and PWV. } \\
\text { Higher frequency of } \\
\text { dairy product } \\
\text { consumption was } \\
\text { significantly associated } \\
\text { with lower PWV values. }\end{array}$ & $\begin{array}{l}\text { Age, sex, race, income, weight, } \\
\text { height, waist circumference, } \\
\text { smoking status, alcohol intake, } \\
\text { physical activity, fasting } \\
\text { glucose, total cholesterol, MAP, } \\
\text { antidiabetic drugs (yes/no), } \\
\text { lipid-lowering drugs (yes/no), } \\
\text { antihypertensive drugs } \\
\text { (yes/no), calorie intake and } \\
\text { non-dairy food groups }\end{array}$ \\
\hline $\begin{array}{l}\text { Livingstone Ket } \\
\text { al, 2013 [25] }\end{array}$ & $\begin{array}{l}\text { UK/Longitudinal } \\
\text { and } \\
\text { cross-sectional }\end{array}$ & $2373 / 56.9 \pm 4.5$ & $26.4 \pm 3.5$ & $\begin{array}{c}144.3 \pm 18.5 / 84.9 \pm \\
10.1\end{array}$ & $11.47 \pm 2.67$ & FFQ [33] & $\begin{array}{l}\text { Milk, cheese, } \\
\text { butter and } \\
\text { cream }\end{array}$ & $346 \mathrm{~g} / \mathrm{d}$ & $\begin{array}{l}\text { Higher intake of dairy } \\
\text { products significantly } \\
\text { decreased PP and SBP } \\
\text { values, but there were } \\
\text { not differences in PWV } \\
\text { results across quartiles } \\
\text { of dairy product } \\
\text { consumption. }\end{array}$ & $\begin{array}{l}\text { Age, alcohol consumption, } \\
\text { smoking habits, social class, } \\
\text { physical activity, total energy } \\
\text { intake, and fat intake, heart } \\
\text { rate, MAP, and drug use. }\end{array}$ \\
\hline $\begin{array}{l}\text { Petersen K et al, } \\
2015 \text { [26] }\end{array}$ & $\begin{array}{c}\text { Australia/ } \\
\text { Cross-sectional }\end{array}$ & $95 / 58.0 \pm 12.0$ & $34.0 \pm 6.9$ & $129 \pm 14 / 73 \pm 10$ & $9.6 \pm 1.8$ & $\begin{array}{l}\text { DQES v2 FFQ of } 3 \\
\text { days [34] }\end{array}$ & $\begin{array}{l}\text { Milk, yogurt } \\
\text { and cheese }\end{array}$ & $387 \mathrm{~g} / \mathrm{d}$ & $\begin{array}{l}\text { Significant inverse } \\
\text { association between } \\
\text { total dairy intake and } \\
\text { yogurt with PWV. }\end{array}$ & $\begin{array}{l}\text { Age, central MAP, BMI, heart } \\
\text { rate and antihypertensive } \\
\text { medication prescription. }\end{array}$ \\
\hline $\begin{array}{l}\text { Recio-Rodriguez } \\
\text { JI et al } 2014 \text { [27] }\end{array}$ & $\begin{array}{c}\text { Spain/ } \\
\text { Cross-sectional }\end{array}$ & $265 / 55.9 \pm 12.2$ & $27.3 \pm 4.3$ & $\begin{array}{c}122.3 \pm 17.9 / 77.6 \pm \\
10.8\end{array}$ & $7.60 \pm 2.00$ & $\begin{array}{l}\text { Semi-quantitative } \\
\text { 137-item FFQ [35] }\end{array}$ & $\begin{array}{l}\text { High-fat dairy } \\
\text { and low-fat } \\
\text { dairy }\end{array}$ & $133.1 \mathrm{~g} / \mathrm{d}$ & $\begin{array}{l}\text { Low-fat dairy products } \\
\text { consumption was } \\
\text { associated with lower } \\
\text { PWV values, but } \\
\text { whole-fat products } \\
\text { increased PWV values. }\end{array}$ & $\begin{array}{l}\text { Age, sex, BMI, smoking, SBP, } \\
\text { total cholesterol, energy intake } \\
\text { and the presence of diabetes, } \\
\text { antihypertensive, antidiabetic } \\
\text { and lipid-lowering drugs. }\end{array}$ \\
\hline
\end{tabular}

BMI: Body mass Index; SBP: Systolic Blood Pressure; DBP: Diastolic Blood Pressure; PWV: Pulse Wave Velocity; m/sec: meters/second; FFQ: Food-frequency questionnaire. NA: Not available. 


\subsection{Risk of Bias}

According to the Quality Assessment Tool for Observational Cohort and Cross-sectional Studies, all studies included in the meta-analysis were considered as having a low risk of bias (Table 3).

Table 3. Quality assessment tool for observational cohort and cross-sectional studies.

\begin{tabular}{|c|c|c|c|c|c|c|c|}
\hline & 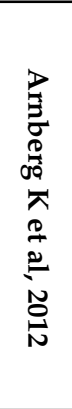 & 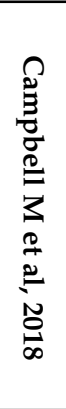 & 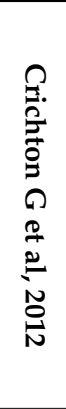 & 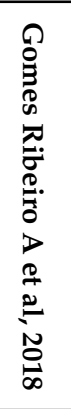 & 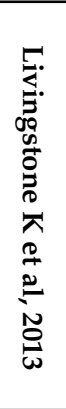 & 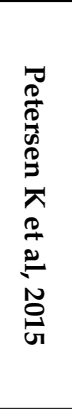 & 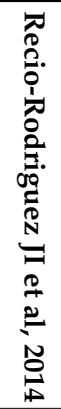 \\
\hline $\begin{array}{l}\text { 1. Was the research question or objective in this paper } \\
\text { clearly stated? }\end{array}$ & Yes & Yes & Yes & Yes & Yes & Yes & Yes \\
\hline $\begin{array}{l}\text { 2. Was the study population clearly specified } \\
\text { and defined? }\end{array}$ & Yes & Yes & Yes & Yes & Yes & Yes & Yes \\
\hline $\begin{array}{l}\text { 3. Was the participation rate of eligible persons at } \\
\text { least } 50 \% \text { ? }\end{array}$ & Yes & NA & Yes & Yes & Yes & Yes & NA \\
\hline $\begin{array}{l}\text { 4. Were all the subjects selected or recruited from the same } \\
\text { or similar populations (including the same time period)? } \\
\text { Were inclusion and exclusion criteria for being in the study } \\
\text { prespecified and applied uniformly to all participants? }\end{array}$ & Yes & Yes & Yes & Yes & Yes & Yes & Yes \\
\hline $\begin{array}{l}\text { 5. Was a sample size justification, power description, } \\
\text { or variance and effect estimates provided? }\end{array}$ & No & No & No & Yes & No & No & Yes \\
\hline $\begin{array}{l}\text { 6. For the analyses in this paper, were the exposure(s) of } \\
\text { interest measured prior to the outcome(s) } \\
\text { being measured? }\end{array}$ & No & No & No & No & No & No & No \\
\hline $\begin{array}{l}\text { 7. Was the timeframe sufficient so that one could } \\
\text { reasonably expect to see an association between exposure } \\
\text { and outcome if it existed? }\end{array}$ & No & No & No & No & No & No & No \\
\hline $\begin{array}{l}\text { 8. For exposures that can vary in amount or level, did the } \\
\text { study examine different levels of the exposure as related } \\
\text { to the outcome (e.g., categories of exposure, or exposure } \\
\text { measured as continuous variable)? }\end{array}$ & No & No & Yes & Yes & Yes & No & No \\
\hline $\begin{array}{l}\text { 9. Were the exposure measures (independent variables) } \\
\text { clearly defined, valid, reliable, and implemented } \\
\text { consistently across all study participants? }\end{array}$ & Yes & Yes & Yes & Yes & Yes & Yes & Yes \\
\hline $\begin{array}{l}\text { 10. Was the exposure(s) assessed more than once } \\
\text { over time? }\end{array}$ & NA & NA & NA & NA & NA & NA & NA \\
\hline $\begin{array}{l}\text { 11. Were the outcome measures (dependent variables) } \\
\text { clearly defined, valid, reliable, and implemented } \\
\text { consistently across all study participants? }\end{array}$ & Yes & Yes & Yes & Yes & Yes & Yes & Yes \\
\hline $\begin{array}{l}\text { 12. Were the outcome assessors blinded to the exposure } \\
\text { status of participants? }\end{array}$ & Yes & Yes & Yes & Yes & Yes & Yes & Yes \\
\hline 13. Was loss to follow-up after baseline $20 \%$ or less? & NA & NA & NA & NA & NA & NA & NA \\
\hline $\begin{array}{l}\text { 14. Were key potential confounding variables measured } \\
\text { and adjusted statistically for their impact on the } \\
\text { relationship between exposure(s) and outcome(s)? }\end{array}$ & Yes & Yes & Yes & Yes & Yes & Yes & Yes \\
\hline
\end{tabular}




\subsection{Meta-Analysis}

Figure 2 presents the ES for each of the dairy products consumed and the PWV. Total dairy products $(\mathrm{ES}=-0.03 ; 95 \% \mathrm{CI}[-0.04,-0.01])$ and cheese $(\mathrm{ES}=-0.04 ; 95 \% \mathrm{CI}[-0.07,-0.01])$ consumption were weak but significantly associated with lower PWV levels. Conversely, milk consumption showed no significant association with PWV (ES $=0.02 ; 95 \%$ CI $[-0.01,0.05]$ ). Heterogeneity in the ES was not important for the three groups of dairy products: total dairy products $(\mathrm{I} 2=0.0 \% ; p=0.839)$, milk (I2 $=0.0 \% ; p=0.930)$, and cheese $(\mathrm{I} 2=4.2 \% ; p=0.352)$.

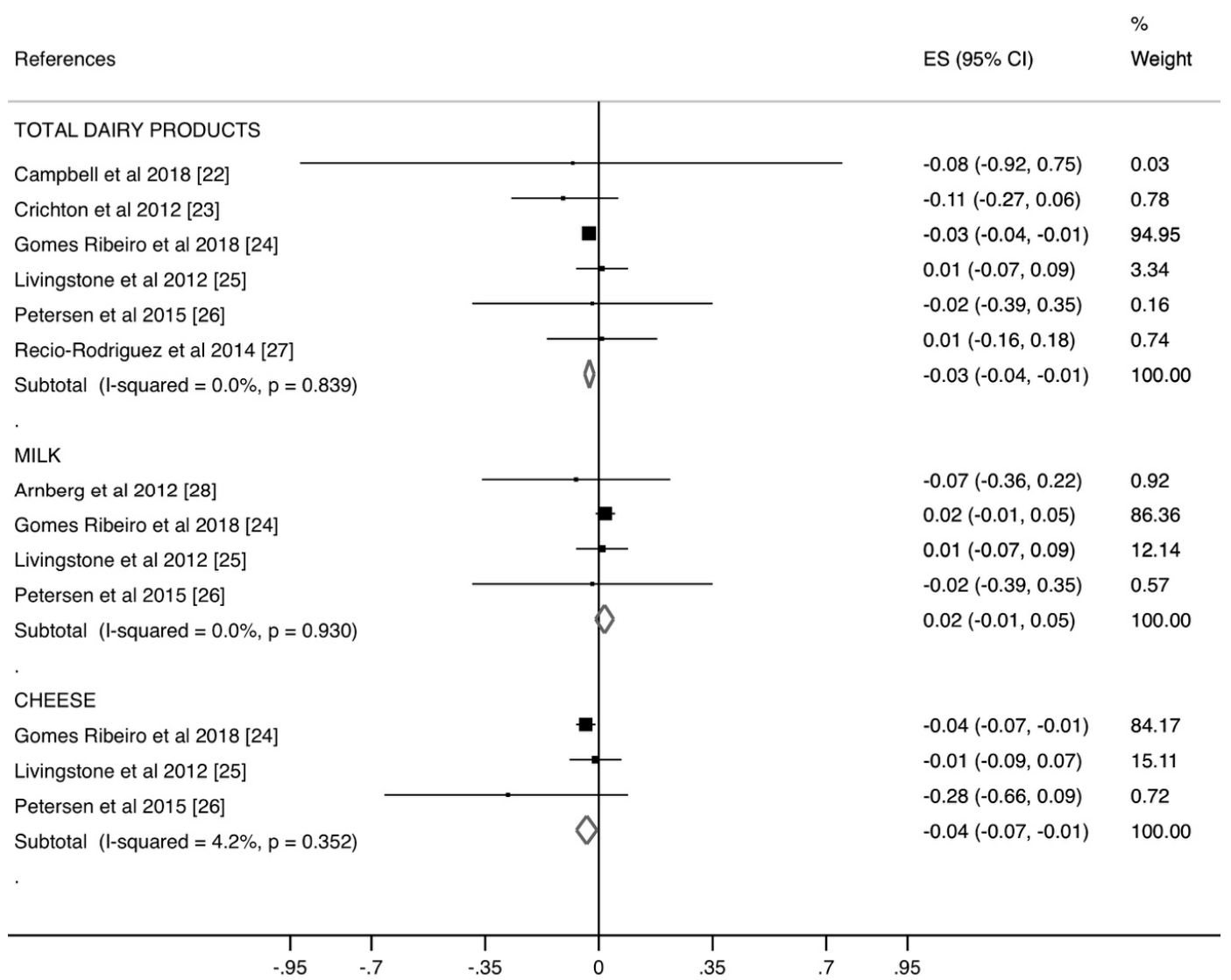

Figure 2. Forest plot of the estimated rate ratio of dairy products consumption and pulse wave velocity (PWV), by type of dairy product and overall.

\subsection{Sensitivity Analysis}

When the impact of individual studies was examined by removing studies from the analysis one at a time, we observed that the pooled ES estimate was modified for total dairy products (ES $=-0.01$, $95 \% \mathrm{CI}[-0.08,0.05])$ and cheese $(\mathrm{ES}=-0.02,95 \% \mathrm{CI}[-0.10,0.06])$ consumption only after removing data from the study by Gomes-Ribeiro et al. (Table 4). 
Table 4. Sensitivity analysis by removing one by one the included studies.

\begin{tabular}{lccc}
\hline References & ES (95\% CI) & $\mathbf{I}^{\mathbf{2}}$ & $p$ \\
\hline TOTAL DAIRY PRODUCTS & & & \\
\hline Campbell M et al, 2018 [22] & $-0.03(-0.04,-0.01)$ & 0.0 & 0.725 \\
Crichton G et al, 2012 [23] & $-0.03(-0.04,-0.01)$ & 0.0 & 0.888 \\
Gomes Ribeiro A et al, 2018 [24] & $-0.01(-0.08,0.05)$ & 0.0 & 0.785 \\
Livingstone K et al, 2013 [25] & $-0.03(-0.05,-0.02)$ & 0.0 & 0.889 \\
Petersen K et al, 2015 [26] & $-0.03(-0.04,-0.01)$ & 0.0 & 0.722 \\
Recio-Rodríguez JI et al, 2014 [27] & $-0.03(-0.04,-0.01)$ & 0.0 & 0.759 \\
MILK & & & \\
\hline Arnberg K et al, 2012 [28] & $0.02(-0.01,0.05)$ & 0.0 & 0.954 \\
Gomes Ribeiro A et al, 2018 [24] & $0.00(-0.07,0.08)$ & 0.0 & 0.866 \\
Livingstone K et al, 2013 [25] & $0.02(-0.01,0.05)$ & 0.0 & 0.815 \\
Petersen K et al, 2015 [26] & $0.02(-0.01,0.05)$ & 0.0 & 0.815 \\
CHEESE & & & \\
\hline Gomes Ribeiro A et al, 2018 [24] & $-0.08(-0.31,0.15)$ & 47.5 & 0.168 \\
Livingstone K et al, 2013 [25] & $-0.04(-0.07,-0.01)$ & 36.0 & 0.211 \\
Petersen K et al, 2015 [26] & $-0.04(-0.06,-0.01)$ & 0.0 & 0.815 \\
\hline
\end{tabular}

\subsection{Meta-Regression}

Due to the limited number of studies, random-effects meta-regression models were conducted only for total dairy product consumption. These analyses indicated that age $(p=0.983)$, BMI $(p=0.518)$, $\operatorname{SBP}(p=0.461), \mathrm{DBP}(p=0.395)$ and PP $(p=0.512)$ were not related to the pooled ES estimates (Table 5$)$.

Table 5. Meta-regressions of the PWV and total dairy products consumption by age, body mass index (BMI), systolic blood pressure (SBP), diastolic blood pressure (DBP) and pulse pressure (PP) of included studies.

\begin{tabular}{lcc}
\hline Covariates & $\mathbb{B}(\mathbf{9 5} \% \mathbf{C I})$ & $p$ \\
\hline Age (years) & $-0.00(-0.01,0.01)$ & 0.983 \\
BMI $\left(\mathrm{kg} / \mathrm{m}^{2}\right)$ & $-0.01(-0.07,0.04)$ & 0.518 \\
SBP $(\mathrm{mmHg})$ & $0.00(-0.00,0.01)$ & 0.461 \\
DBP (mmHg) & $0.00(-0.01,0.02)$ & 0.395 \\
PP $(\mathrm{mmHg})$ & $0.00(-0.01,0.01)$ & 0.512 \\
\hline
\end{tabular}

SBP: Systolic blood pressure; DBP: Diastolic blood pressure; PP: Pulse pressure.

\subsection{Publication Bias}

The Harbord modified test for publication bias was performed only for total dairy products and showed no evidence of publication bias $(p=0.877)$ (Figure 3$)$. 


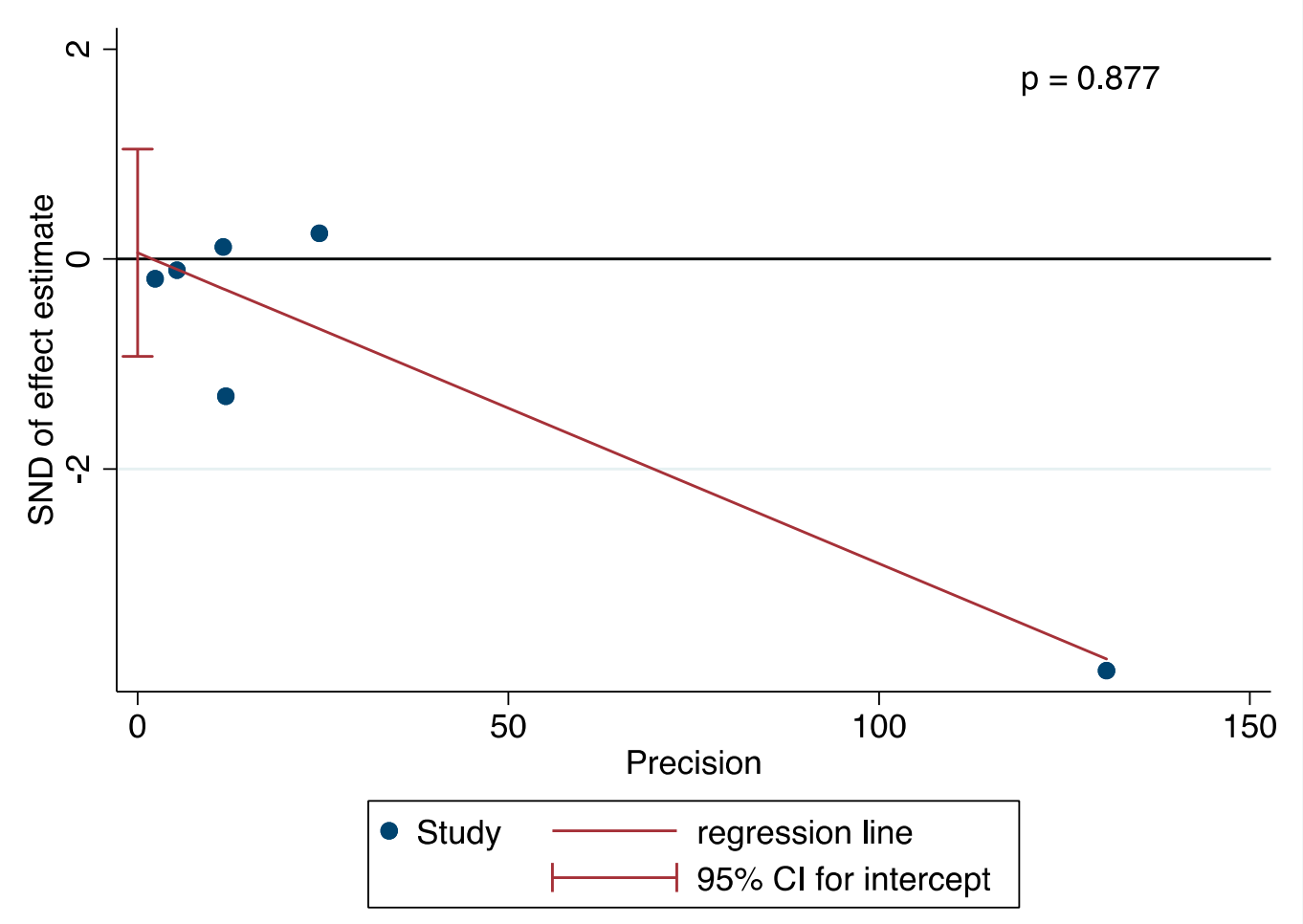

Figure 3. Assessment of potential publication bias by Harbord test.

\section{Discussion}

This systematic review and meta-analysis synthetized the current available evidence regarding the association between dairy product consumption and PWV. We found a significant association of total dairy and cheese consumption with slightly lower PWV levels. However, no association between milk consumption and PWV was observed.

In our analysis, we found an overall statistically significant association between total dairy product intake and lower PWV, although the effect estimates were small. This association was mainly driven by the study by Gomez-Ribeiro et al. However, it is worth noting that, of the six studies analyzed in the category of total dairy products, only three separately analyzed the consumption of whole-fat and low-fat dairy [24,26,27]. While two studies did not find an association between PWV and whole-fat dairy, Recio-Rodriguez found opposite associations based on the fat content. Specifically, for every $100 \mathrm{~g} /$ day increase in low-fat dairy intake there was a decrease in PWV of $0.10 \mathrm{~m} / \mathrm{s}(p=0.011)$, while the same amount of high-fat dairy resulted in a similar increase in PWV $(0.109 \mathrm{~m} / \mathrm{s} ; p=0.038)$. In another cross-sectional study, Crichton et al. found that dairy product intake $(80.4 \%$ of which was reduced-fat milk) was inversely associated with PWV. Low-fat dairy, but not whole-fat dairy, was associated with lower PWV in the ELSA-Brazil study [24]. Due to the cross-sectional nature of the previous results [27], these findings should be interpreted with caution. Moreover, given that data from another meta-analysis supports a negative association between total dairy product intake and CVD risk [12], together with the null association of whole-fat dairy intake reported in some studies [24,26], we suggest that conclusions for whole-fat dairy products cannot be made until we have results from well-designed follow-up or experimental studies, in accordance with all authors of the studies included in the systematic review which stated that more prospective, randomized, population-based studies are needed to reinforce their results.

Blood pressure is one of the major determinants of arterial stiffness [36]. The various components of dairy products may explain the health benefits found in different studies. For example, the bioactive peptides present in dairy products may inhibit the angiotensin-I-converting enzyme, which is involved 
in the regulation of blood pressure [37,38]. Similarly, milk-derived bioactive peptides produced by the proteolysis of casein and whey have been suggested to play a role in atherosclerosis. Consistent with these biochemical mechanisms, in the prospective cohort from the Caerphilly Prospective Study, those with the highest milk intake showed a lower SBP when compared with those who did not consume milk, and milk and dairy product intake was not associated with arterial stiffening. Indeed, only butter intake was positively associated with blood pressure and arterial stiffness indicators in that study [25]. The authors highlighted that they only included whole-fat milk in their analysis. We did not include butter in this meta-analysis because from the seven studies included in this meta-analysis, only the cross-sectional ELSA-Brasil study included butter separately in their analyses [24], reporting a significant negative association between butter intake and carotid-femoral PWV, but no association with SBP and PP. Our pooled estimates did not show a significant association between milk intake and arterial stiffening; however, due to the scarcity of studies, these estimates should be interpreted with caution.

With regard to cheese consumption, three studies included in this meta-analysis showed an overall significant association between cheese consumption and a lower PWV, although this finding was mostly driven by the results from the study by Gomes-Ribeiro et al. In their cross-sectional study, the authors reported that cheese (one serving per day) was inversely associated with PVW (cfPWV $=-0.02 \mathrm{~m} / \mathrm{s}[-0.04,-0.01])$. As our results were strongly influenced by this study, we suggest that more research should address this issue. Similarly, the results of research analyzing the effect of dietary and nutrient interventions on the treatment of arterial stiffness, although limited, supports that Lactobacillus helveticus-fermented milk products and products containing tripeptides [39] improve arterial stiffness (Cohen's $d=0.15-0.33$ ) in hypertensive patients [40]. In the case of cheese consumption, because this dairy product contains a high amount of salt, further research is needed to investigate whether the specific type of cheese is relevant. Finally, yogurt was not evaluated in this meta-analysis because our search retrieved only two studies that specifically assessed its effect on arterial stiffness [24,26], although the ES estimates for these studies indicated a lower inverse association between yogurt consumption and PWV $(-0.04[-0.07,-0.01])$. Thus, these results are inconclusive. Likewise, the evidence for a hypotensive effect of yogurt is controversial, as although some studies suggest a hypotensive effect [41,42], a previous meta-analysis reported moderate- to high-quality evidence that the consumption of high-fat dairy, cheese, yogurt and fermented dairy products are not associated with the risk of hypertension [42].

\section{Limitations}

Some limitations in this systematic review and meta-analysis should be acknowledged: (1) the limited number of studies did not allow us to specifically analyze the association of each type of dairy product; (2) we could not evaluate changes or the effect of interventions on the relationship between milk intake and arterial stiffness due to the cross-sectional nature of the included studies; (3) the study conducted by Gomes-Ribeiro and colleagues had a markedly greater sample size when compared to the other studies, although sensitivity analyses did not show a change in the results after removing this study; (4) different validated food frequency questionnaires were used across studies, therefore, the data for dairy product consumption were not similar across studies which might affect the reliability of our results; and (5) although the Cochrane Handbook recommends that a meta-regression analyses only be conducted when there are 10 or more studies in the meta-analysis, we performed this statistical test for total dairy product consumption in order to obtain a picture of the impact of certain risk factors of disputed influence on PWV, such as age or blood pressure, on our estimates. Thus, the findings of these analyses should be interpreted with caution.

\section{Conclusions}

Overall, we found no detrimental effect of dairy product consumption on arterial stiffness, as measured by PWV. An inverse association with PWV was found for total dairy and cheese 
consumption. However, our results should be interpreted with caution because most of the evidence comes from cross-sectional studies (seven studies). Well-designed, randomized controlled trials and follow-up studies are warranted to clarify the role of dairy products on arterial stiffness.

Author Contributions: A.D.-F. performed the literature search, screening, data extraction, data analysis, software and manuscript writing; C.Á.-B. and V.M.-V. contributed to data analysis, manuscript writing, conceptualization and methodology; I.C.-R. performed the literature search, screening, data extraction, data analysis, software and manuscript writing and methodology; M.S.-P. contributed in the conceptualization and manuscript writing; J.I.R.-R. contributed in the methodology and manuscript writing and revision. All authors have approved the final version of the manuscript.

Funding: This research received no external funding.

Conflicts of Interest: The authors declare no conflict of interest.

\section{References}

1. Mendis, S. Global Status Report on Noncommunicable Diseases; World Health Organization: Geneva, Swizerland, 2014.

2. Abargouei, A.S.; Janghorbani, M.; Salehi-Marzijarani, M.; Esmaillzadeh, A. Effect of dairy consumption on weight and body composition in adults: A systematic review and meta-analysis of randomized controlled clinical trials. Int. J. Obes. (Lond) 2012, 36, 1485-1493. [CrossRef] [PubMed]

3. Aune, D.; Norat, T.; Romundstad, P.; Vatten, L.J. Dairy products and the risk of type 2 diabetes: A systematic review and dose-response meta-analysis of cohort studies. Am. J. Clin. Nutr. 2013, 98, 1066-1083. [CrossRef] [PubMed]

4. Ralston, R.A.; Lee, J.H.; Truby, H.; Palermo, C.E.; Walker, K.Z. A systematic review and meta-analysis of elevated blood pressure and consumption of dairy foods. J. Hum. Hypertens. 2012, 26, 3-13. [CrossRef] [PubMed]

5. Soedamah-Muthu, S.S.; de Goede, J. Dairy consumption and cardiometabolic diseases: Systematic review and updated meta-analyses of prospective cohort studies. Curr. Nutr. Rep. 2018, 7, 171-182. [CrossRef] [PubMed]

6. Vlachopoulos, C.; Aznaouridis, K.; Stefanadis, C. Prediction of cardiovascular events and all-cause mortality with arterial stiffness: A systematic review and meta-analysis. J. Am. Coll. Cardiol. 2010, 55, 1318-1327. [CrossRef] [PubMed]

7. García-Hermoso, A.; Martínez-Vizcaíno, V.; Gomez-Marcos, M.; Cavero-Redondo, I.; Recio-Rodriguez, J.I.; García-Ortiz, L. Ideal cardiovascular health and arterial stiffness in spanish adults-the evident study. J. Stroke Cerebrovasc. Dis. 2018, 27, 1386-1394. [CrossRef]

8. Li, P.; Wang, L.; Liu, C. Overweightness, obesity and arterial stiffness in healthy subjects: A systematic review and meta-analysis of literature studies. Postgrad. Med. 2017, 129, 224-230. [CrossRef] [PubMed]

9. Muhammad, I.F.; Borné, Y.; Östling, G.; Kennbäck, C.; Gottsäter, M.; Persson, M.; Nilsson, P.M.; Engström, G. Arterial stiffness and incidence of diabetes: A population-based cohort study. Diabetes Care 2017, 40, 1739-1745. [CrossRef] [PubMed]

10. Mensink, P. Effects of Saturated Fatty Acids on Serum Lipids and Lipoproteins: A Systematic Review and Regression Analysis; World Health Organization: Geneva, Swizerland, 2016.

11. Dehghan, M.; Mente, A.; Rangarajan, S.; Sheridan, P.; Mohan, V.; Iqbal, R.; Gupta, R.; Lear, S.; Wentzel-Viljoen, E.; Avezum, A.; et al. Association of dairy intake with cardiovascular disease and mortality in 21 countries from five continents (PURE): A prospective cohort study. Lancet 2018, 392, 2288-2297. [CrossRef]

12. Fontecha, J.; Calvo, M.; Juarez, M.; Gil, A.; Martínez-Vizcaino, V. Milk and dairy product consumption and cardiovascular diseases: An overview of systematic reviews and meta-analyses. Adv. Nutr. 2019. [CrossRef]

13. Alvarez-Bueno, C.; Cavero-Redondo, I.; Martinez-Vizcaino, V.; Sotos-Prieto, M.; Ruiz, J.; Gil, A. Effects of milk and dairy product consumption on type 2 diabetes: Overview of systematic reviews and meta-analyses. Adv. Nutr. 2019. [CrossRef]

14. Cavero-Redondo, I.; Alvarez-Bueno, C.; Sotos-Prieto, M.; Gil, A.; Martinez-Vizcaino, V.; Ruiz, J. Milk and dairy product consumption and risk of mortality: An overview of systematic reviews and meta-analyses. Adv. Nutr. 2019. [CrossRef] 
15. Laurent, S.; Cockcroft, J.; Van Bortel, L.; Boutouyrie, P.; Giannattasio, C.; Hayoz, D.; Pannier, B.; Vlachopoulos, C.; Wilkinson, I.; Struijker-Boudier, H.; et al. Expert consensus document on arterial stiffness: Methodological issues and clinical applications. Eur. Heart. J. 2006, 27, 2588-2605. [CrossRef]

16. Moher, D.; Liberati, A.; Tetzlaff, J.; Altman, D.G.; Group, P. Preferred reporting items for systematic reviews and meta-analyses: The PRISMA statement. J. Clin. Epidemiol. 2009, 62, 1006-1012. [CrossRef] [PubMed]

17. Cochrane Handbook for Systematic Reviews of Interventions. Available online: http:/handbook.cochrane.org (accessed on 12 September 2018).

18. National Heart, Lung and Blood Institute. Quality Assessment Tool for Observational Cohort and Cross-Sectional Studies. Available online: https:/ / www.nhlbi.nih.gov/health-topics/study-quality-assessment-tools (accessed on 21 September 2018).

19. Mantel, N.; Haenszel, W. Statistical aspects of the analysis of data from retrospective studies of disease. J. Natl. Cancer Inst. 1959, 22, 719-748. [PubMed]

20. Cohen, J. Statistical Power Analysis for the Behavioral Sciences; Lawrence Erlbaum Associates: Hillsdale, NJ, USA, 1988.

21. Harbord, R.M.; Egger, M.; Sterne, J.A. A modified test for small-study effects in meta-analyses of controlled trials with binary endpoints. Stat. Med. 2006, 25, 3443-3457. [CrossRef] [PubMed]

22. Campbell, M.S.; Fleenor, B.S. Whole grain consumption is negatively correlated with obesity-associated aortic stiffness: A hypothesis. Nutrition 2018, 45, 32-36. [CrossRef] [PubMed]

23. Crichton, G.E.; Elias, M.F.; Dore, G.A.; Abhayaratna, W.P.; Robbins, M.A. Relations between dairy food intake and arterial stiffness: Pulse wave velocity and pulse pressure. Hypertension 2012, 59, 1044-1051. [CrossRef] [PubMed]

24. Ribeiro, A.G.; Mill, J.G.; Cade, N.V.; Velasquez-Melendez, G.; Matos, S.M.A.; Molina, M.D.C.B. Associations of dairy intake with arterial stiffness in brazilian adults: The Brazilian longitudinal study of adult health (ELSA-Brasil). Nutrients 2018, 10, 701. [CrossRef]

25. Livingstone, K.M.; Lovegrove, J.A.; Cockcroft, J.R.; Elwood, P.C.; Pickering, J.E.; Givens, D.I. Does dairy food intake predict arterial stiffness and blood pressure in men?: Evidence from the Caerphilly Prospective Study. Hypertension 2013, 61, 42-47. [CrossRef] [PubMed]

26. Petersen, K.S.; Keogh, J.B.; Meikle, P.J.; Garg, M.L.; Clifton, P.M. Dietary predictors of arterial stiffness in a cohort with type 1 and type 2 diabetes. Atherosclerosis 2015, 238, 175-181. [CrossRef] [PubMed]

27. Recio-Rodriguez, J.I.; Gomez-Marcos, M.A.; Patino-Alonso, M.C.; Sanchez, A.; Agudo-Conde, C.; Maderuelo-Fernandez, J.A.; Garcia-Ortiz, L.; Group, E. Association between fat amount of dairy products with pulse wave velocity and carotid intima-media thickness in adults. Nutr. J. 2014, 13, 37. [CrossRef] [PubMed]

28. Arnberg, K.; Larnkjær, A.; Michaelsen, K.F.; Mølgaard, C. Central adiposity and protein intake are associated with arterial stiffness in overweight children. J. Nutr. 2012, 142, 878-885. [CrossRef]

29. Rasmussen, L.B.; Matthiessen, J.; Biltoft-Jensen, A.; Tetens, I. Characteristics of misreporters of dietary intake and physical activity. Public Health Nutr. 2007, 10, 230-237. [CrossRef] [PubMed]

30. Diet History Questionnaire, Version 2.0. National Institutes of Health, Epidemiology and Genomics Research Program, National Cancer Institute. 2010. Available online: https:/ / epi.grants.cancer.gov/dhq2/ (accessed on 18 April 2018).

31. Riboli, E.; Kaaks, R. The EPIC Project: Rationale and study design. European Prospective Investigation into Cancer and Nutrition. Int. J. Epidemiol. 1997, 26 (Suppl. 1), S6-S14. [CrossRef] [PubMed]

32. Molina, M.e.C.; Benseñor, I.M.; Cardoso, L.e.O.; Velasquez-Melendez, G.; Drehmer, M.; Pereira, T.S.; Faria, C.P.; Melere, C.; Manato, L.; Gomes, A.L.; et al. Reproducibility and relative validity of the Food Frequency Questionnaire used in the ELSA-Brasil. Cad. Saude Publica 2013, 29, 379-389. [CrossRef]

33. Fehily, A.M.; Yarnell, J.W.; Bolton, C.H.; Butland, B.K. Dietary determinants of plasma lipids and lipoproteins: The Caerphilly Study. Eur. J. Clin. Nutr. 1988, 42, 405-413. [PubMed]

34. Hodge, A.; Patterson, A.J.; Brown, W.J.; Ireland, P.; Giles, G. The Anti Cancer Council of Victoria FFQ: Relative validity of nutrient intakes compared with weighed food records in young to middle-aged women in a study of iron supplementation. Aust. N. Z. J. Public Health 2000, 24, 576-583. [CrossRef] [PubMed] 
35. Fernández-Ballart, J.D.; Piñol, J.L.; Zazpe, I.; Corella, D.; Carrasco, P.; Toledo, E.; Perez-Bauer, M.; Martínez-González, M.A.; Salas-Salvadó, J.; Martín-Moreno, J.M. Relative validity of a semi-quantitative food-frequency questionnaire in an elderly Mediterranean population of Spain. Br. J. Nutr. 2010, 103, 1808-1816. [CrossRef] [PubMed]

36. Laurent, S.; Boutouyrie, P.; Lacolley, P. Structural and genetic bases of arterial stiffness. Hypertension 2005, 45, 1050-1055. [CrossRef]

37. FitzGerald, R.J.; Murray, B.A.; Walsh, D.J. Hypotensive peptides from milk proteins. J. Nutr. 2004, 134, 980S-988S. [CrossRef] [PubMed]

38. Nongonierma, A.B.; FitzGerald, R.J. Bioactive properties of milk proteins in humans: A review. Peptides 2015, 73, 20-34. [CrossRef] [PubMed]

39. Jauhiainen, T.; Rönnback, M.; Vapaatalo, H.; Wuolle, K.; Kautiainen, H.; Groop, P.H.; Korpela, R. Long-term intervention with lactobacillus helveticus fermented milk reduces augmentation index in hypertensive subjects. Eur. J. Clin. Nutr. 2010, 64, 424-431. [CrossRef] [PubMed]

40. Pase, M.P.; Grima, N.A.; Sarris, J. The effects of dietary and nutrient interventions on arterial stiffness: A systematic review. Am. J. Clin. Nutr. 2011, 93, 446-454. [CrossRef]

41. Harding, J.L.; Shaw, J.E.; Peeters, A.; Guiver, T.; Davidson, S.; Magliano, D.J. Mortality trends among people with type 1 and type 2 diabetes in Australia: 1997-2010. Diabetes Care 2014, 37, 2579-2586. [CrossRef]

42. Drouin-Chartier, J.P.; Brassard, D.; Tessier-Grenier, M.; Côté, J.A.; Labonté, M.; Desroches, S.; Couture, P.; Lamarche, B. Systematic review of the association between dairy product consumption and risk of cardiovascular-related clinical outcomes. Adv. Nutr. 2016, 7, 1026-1040. [CrossRef]

(C) 2019 by the authors. Licensee MDPI, Basel, Switzerland. This article is an open access article distributed under the terms and conditions of the Creative Commons Attribution (CC BY) license (http:/ / creativecommons.org/licenses/by/4.0/). 